\title{
Serial interval and incubation period of COVID-19: a systematic review and meta- analysis
}

Muluneh Alene ${ }^{1}$, Leltework Yismaw ${ }^{1}$, Moges Agazhe Assemie ${ }^{1}$, Daniel Bekele Ketema ${ }^{1}$, Wodaje Gietaneh ${ }^{1}$ and Tilahun Yemanu Birhan ${ }^{2 *}$

\begin{abstract}
Background: Understanding the epidemiological parameters that determine the transmission dynamics of COVID19 is essential for public health intervention. Globally, a number of studies were conducted to estimate the average serial interval and incubation period of COVID-19. Combining findings of existing studies that estimate the average serial interval and incubation period of COVID-19 significantly improves the quality of evidence. Hence, this study aimed to determine the overall average serial interval and incubation period of COVID-19.
\end{abstract}

Methods: We followed the PRISMA checklist to present this study. A comprehensive search strategy was carried out from international electronic databases (Google Scholar, PubMed, Science Direct, Web of Science, CINAHL, and Cochrane Library) by two experienced reviewers (MAA and DBK) authors between the 1st of June and the 31st of July 2020. All observational studies either reporting the serial interval or incubation period in persons diagnosed with COVID-19 were included in this study. Heterogeneity across studies was assessed using the $\mathrm{I}^{2}$ and Higgins test. The NOS adapted for cross-sectional studies was used to evaluate the quality of studies. A random effect Metaanalysis was employed to determine the pooled estimate with 95\% (Cl). Microsoft Excel was used for data extraction and $\mathrm{R}$ software was used for analysis.

Results: We combined a total of 23 studies to estimate the overall mean serial interval of COVID-19. The mean serial interval of COVID-19 ranged from 4.2 to 7.5 days. Our meta-analysis showed that the weighted pooled mean serial interval of COVID-19 was 5.2 (95\%Cl: 4.9-5.5) days. Additionally, to pool the mean incubation period of COVID19, we included 14 articles. The mean incubation period of COVID-19 also ranged from 4.8 to 9 days. Accordingly, the weighted pooled mean incubation period of COVID-19 was 6.5 (95\%Cl: 5.9-7.1) days.

Conclusions: This systematic review and meta-analysis showed that the weighted pooled mean serial interval and incubation period of COVID-19 were 5.2, and 6.5 days, respectively. In this study, the average serial interval of COVID-19 is shorter than the average incubation period, which suggests that substantial numbers of COVID-19 cases will be attributed to presymptomatic transmission.

Keywords: COVID-19, Serial interval, Incubation period, Meta-analysis

\footnotetext{
* Correspondence: yemanu.tilahun@gmail.com

${ }^{2}$ Department of Epidemiology and Biostatistics, Institute of Public Health, College of Medicine and Health Science, University of Gondar, Gondar, Ethiopia

Full list of author information is available at the end of the article
}

(C) The Author(s). 2021 Open Access This article is licensed under a Creative Commons Attribution 4.0 International License, which permits use, sharing, adaptation, distribution and reproduction in any medium or format, as long as you give appropriate credit to the original author(s) and the source, provide a link to the Creative Commons licence, and indicate if changes were made. The images or other third party material in this article are included in the article's Creative Commons licence, unless indicated otherwise in a credit line to the material. If material is not included in the article's Creative Commons licence and your intended use is not permitted by statutory regulation or exceeds the permitted use, you will need to obtain permission directly from the copyright holder. To view a copy of this licence, visit http://creativecommons.org/licenses/by/4.0/. The Creative Commons Public Domain Dedication waiver (http://creativecommons.org/publicdomain/zero/1.0/) applies to the data made available in this article, unless otherwise stated in a credit line to the data. 


\section{Background}

The 2019 Coronavirus Disease (COVID-19) continues to be one of the potential clinical and public health issues in the global population [1]. Globally, from the outbreak of the virus up to August 5, 2020, 18 million total confirmed cases and 700, 000 deaths were reported [2]. Rapid spread of COVID-19 causes an enormous impact on social, economic and health care system in the world [3]. Effective treatment to block the spread of COVID19 is not developed yet, hence countries implement non-treatment intervention such as social distancing, isolation, face mask and quarantine to reduce its rapid transmission $[4,5]$.

Existing evidence showed that most of the COVID-19 cases are missed by screening due to they are unaware they were exposed, and not developed symptoms yet [5]. In the absence of strong public health interventions, preliminary estimates showed that the basic reproduction number of Severe Acute Respiratory Syndrome Coronovirus-2 (SARS-CoV-2) ranged from 2.8 to 5.5 [6]. Serial interval and incubation period are the two main epidemiological parameters that determine the transmission dynamics of infectious diseases [7]. Serial interval is defined as the time from illness onset in the primary case to illness onset in the secondary case, while incubation period is the time from infection occurred to the onset of signs and symptoms.

Previous studies reported that the average serial interval of COVID-19 is shorter than the average incubation period, which suggests that a substantial proportion of presymptomatic transmission $[8,9]$. This makes it difficult to trace contacts due to the rapid turnover of case generations. An observational study that aimed to provide the epidemiological parameters of COVID-19 using seven countries data revealed that the mean incubation period and serial interval were 7.44 days and 6.70 days, respectively [10]. A study that compares the incubation period of SARS-CoV-2, severe acute respiratory syndrome coronavirus (SARS-CoV), and middle east respiratory syndrome coronavirus (MERS-CoV) reported that no observable difference in the incubation was noted between them [11].

Globally, a number of studies were conducted to estimate the average serial interval and incubation period of COVID-19. However, the reported estimate of serial interval and incubation period in these fragmented studies vary depending on the number of study participants recruited, the type of design employed, the data collection period, and the country in which the study conducted. Combined findings of existing studies significantly strengthen the quality of evidence investigating the average estimate of serial interval and incubation period of COVID-19. Thus, this meta-analysis was aimed to determine the overall pooled mean serial interval and incubation period of COVID-19 using available evidences. The findings of this study are intended to improve policies and strategies for better prevention and control of COVID-19.

\section{Methods \\ Source of information}

We identified relevant studies through searching electronic databases and gray literatures. Additionally, we were searched from the reference lists of all the included studies to identify any other studies that may have been missed by our search strategy.

\section{Searching for studies}

We followed the preferred reporting items for systematic review and meta-analysis (PRISMA) checklist for this study [12]. A comprehensive search strategy was performed from international electronic databases (Google Scholar, PubMed, Science Direct, Web of Science, CINA HL, and Cochrane Library) by two experienced review (MAA and DBK) authors between 1st of June and the 31st of July 2020. The following searching terms are used from the above databases: "serial interval" OR "generation time" AND "incubation period" OR "infectious period" AND "COVID-19" OR "SARS-CoV-2" OR "novel coronavirus".

\section{Inclusion criteria}

\section{Design}

All observational studies either reporting the serial interval or incubation period of COVID-19.

\section{Study setting}

Worldwide.

\section{Population}

All age group.

\section{Publication status}

All published and unpublished articles.

\section{Language}

Only studies reporting using the English language.

\section{Publication date}

Published from the 1st of January 2020 to the 30th of June, 2020.

\section{Exclusion criteria}

Articles that were not fully accessed after at least two email contacts of the principal investigator were excluded. In addition, we excluded case reports, letters, and review articles. 


\section{Study selection}

The eligibility assessment was undertaken by two (WG and TYB) authors, independently. The disagreement between two reviewers were fixed by consensus.

\section{Outcome measures and data extraction}

This study has two outcome variables. The first is the average estimate of serial interval. The serial interval is defined as the time from illness onset in the primary case to illness onset in the secondary case. It also measured from pairs of cases with a clear infector-infectee relationship. The second outcome variable is the average estimate of the incubation period. Incubation period is defined as the time from infection occurred to the onset of signs and symptoms. It was measured with cases of a well-defined period of exposure and symptom onset. Screening of studies and all essential data from the included studies were extracted independently by two (MA and LY) of the authors. This form includes the last name of the first author, country, data collection period, sample size, average estimate, standard deviation, and 95\% confidence intervals. The same data extraction form was used for both outcomes. Discrepancies between the two reviewers was resolved by consensus involving all authors.

\section{Assessing the risk of bias}

Two experienced reviewers (MA and DBK) were assessed the risk of bias of the included articles. The Newcastle-Ottawa Scale (NOS) adapted for crosssectional studies was used to evaluate the quality of studies [13]. This tool includes three categories with a maximum score of 9 points. The first is the "selection" category, which accounts for a maximum of 4 points, the second is the "Comparability" category, which accounts for a maximum of 2 points, and the third is "outcome" which accounts a maximum of 3 points. Based on the composite score from this three categories, the studies were classified as good quality if the score $\geq 6$ points, fair quality 2 to 5 points inclusively and poor quality $\leq 1$ point.

\section{Data processing and analysis}

A meta-analysis of continuous outcomes was employed for this study. We analyzed the data sets for each outcome variable (serial interval and incubation period). After extracting all essential data using Microsoft Excel, data were exported to $\mathrm{R}$ 4.0.2 statistical software for meta-analysis. In order to pool the results of included studies in a consistent format, we estimated the sample mean and standard deviation for studies that report median and interquartile range [14]. To determine the extent of variation between the studies, we did a heterogeneity test using the Higgins method, that was quantified by $\mathrm{I}^{2}$ value [15]. Weighted average using the inverse variance method was used to estimate the pooled average. A random-effect meta-analysis with an estimation of DerSimonian and Laird method was performed. The publication bias was also assessed using a funnel plot and Egger's tests [16]. The pooled average estimates with $95 \% \mathrm{CI}$ confidence interval was presented using forest plots.

\section{Results \\ Search results}

Figure 1 indicates the overall flow of study selection, literature search and number of the included studies. During electronic literature search 14,247 articles were identified and 14, 140 duplicated articles were removed. After meticulous review of the whole articles, 28 studies that fulfill the suitability standards were included. From the included studies, a single study might report both outcomes (serial interval and incubation period). Accordingly, a total of 23 and 14 studies were combined to estimate the mean serial interval, and incubation period of COVID-19, respectively.

\section{Description of the included studies}

All the included studies are cross-sectional, and half of them were preprints. Majority of studies included in this study are conducted in China. We included a total of 23 articles to pool the mean of serial interval of COVID-19. The minimum and maximum pairs of COVID-19 patients among the included studies were 6 [17] and 1407 [18], respectively. Among the included studies, the mean serial interval of COVID-19 was ranged from 4. 2 days [19] to 7.5 days [17] (Table 1).

Similarly, to pool the mean incubation period of COVID-19, a total of 14 articles were included. Among those, the minimum sample size was 10 [17] and the maximum was 183 [20]. The mean incubation period of COVID-19 ranged from 4.8 days [20] to 9 days [19] (Table 2).

\section{Pooled average estimate of serial interval and incubation period}

In this study, a total of 3924 pairs of COVID-19 patients were included to pool the mean serial interval. Accordingly, the weighted overall mean serial interval of COVID-19 was 5.2 (95\%CI: 4.9-5.5) days (Fig. 2). Likewise, a total of 1, 453 COVID-19 patients were included to pool the overall incubation period of COVID-19. Consequently, the weighted pooled mean incubation period of COVID-19 was 6.5 (95\%CI: 5.9-7.1) days (Fig. 3).

Of the included studies to pool the mean serial interval of COVID-19, our summary quality assessment showed that nearly three-fourth $(73.9 \%)$ of the studies 


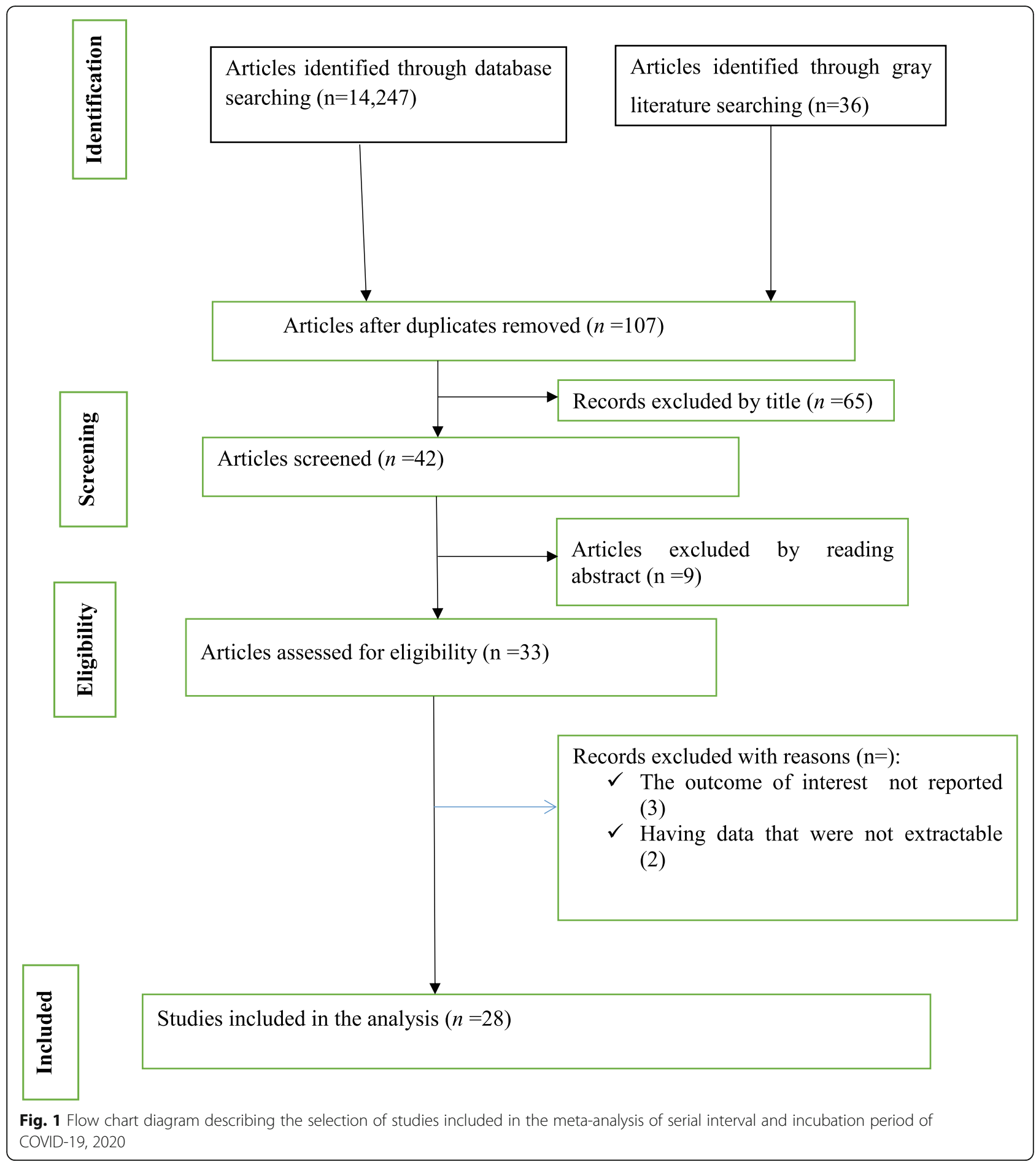

had a good quality (Table S1). Similarly, among the included studies to pool the mean incubation period of COVID-19, about $71.4 \%$ of studies had a good quality (Table S2). We assessed the issue of publication bias by visual inspection of funnel plot and by using Egger's regression test. Though the funnel plot looks asymmetrical the Egger's test showed that no relationship between the effect size and its precision (Fig. 4).

\section{Discussion}

The current study has two main objectives. The first objective is to determine the overall mean serial interval of 
Table 1 Descriptions of the included studies conducted on the average estimate of serial interval of COVID-19, 2020

\begin{tabular}{|c|c|c|c|c|c|c|c|}
\hline No. & First author & Country & Study period & $\begin{array}{l}\text { Sample size (in } \\
\text { pairs) }\end{array}$ & $\begin{array}{l}\text { Mean in } \\
\text { days }\end{array}$ & $\begin{array}{l}\text { Standard } \\
\text { deviation }\end{array}$ & $\begin{array}{l}95 \% \mathrm{Cl} \text { for } \\
\text { mean }\end{array}$ \\
\hline 1. & Aghaali et al & Iran & February 20,2020 & 37 & 4.55 & 3.3 & NR \\
\hline 2. & Ali et al & China & January 9 to February 13, 2020 & 677 & 5.1 & 5.3 & $4.7-5.5$ \\
\hline 3. & Bi et al & China & Jan 14 to February 12, 2020 & 48 & $6 \cdot 3$ & 4.2 & $5.2-7 \cdot 6$ \\
\hline 4. & Bui et al & Vietnam & January 29 to March 24,2020 & 9 & 5.8 & 3.6 & NR \\
\hline 5 & Cereda et al. & Italy & March 82,020 & 90 & 6.6 & 28 & $0.7-19$ \\
\hline 6. & Chan et al & China & January 23 to April 6, 2020 & 47 & 6.5 & 4.7 & NR \\
\hline 7. & Cheng et al & Taiwan & January 15 to February 26,2020 & 12 & 7.0 & 5.8 & $3.7-13.2$ \\
\hline 8. & Du et al & China & January 20 to February 19, 2020 & 339 & 5.3 & 5.3 & $4.7-5.9$ \\
\hline 9. & He et al & China & January 21 to March 6, 2020 & 77 & 5.8 & 4.5 & $4.8-6.8$ \\
\hline 10. & Li et al & China & $\begin{array}{l}\text { January } 21,2020 \text {, to February } 29 \text {, } \\
2020 .\end{array}$ & 337 & 5.8 & 3.9 & $5: 4-6: 2$ \\
\hline 11. & Li et al & China & January 22, 2020 & 6 & 7.5 & 3.4 & $5.3-19$ \\
\hline 12. & Liu et al & China & January 1, to March 12, 2020 & 116 & 5.8 & 3.2 & \\
\hline 13. & Najafi et al & Iran & February 22 to March 29, 2020 & 21 & 5.7 & 3.9 & NR \\
\hline 14. & $\begin{array}{l}\text { Nishiuraa } \\
\text { et al }\end{array}$ & Japan & February 12, 2020 & 28 & 4.7 & 2.9 & $3.7-6.0$ \\
\hline 15. & Kowk et al & China & February 13,2020 & 26 & 4.6 & 3.3 & $3.4-5.9$ \\
\hline 16. & Tindale et al & Singapore & January 19 to February 26,2020 & 93 & 4.6 & 0.9 & $2.7-6.4$ \\
\hline 17. & Tindale et al & Tianjin & January 21 to February 27,2020 & 135 & 4.2 & 4.0 & $3.4-5.0$ \\
\hline 18. & Viego et al & Argentina & March 20 to May 8, 2020 & 13 & 5.5 & 5.0 & $2.8-8.1$ \\
\hline 19. & Xu et al & China & January 15 to February 29, 2020 & 1407 & 5.2 & 5.3 & $4.6,5.8$ \\
\hline 20. & Yang et al & China & January 20, 2020 & 152 & 4.6 & 4.4 & $3.7-5.5$ \\
\hline 21. & You et al & China & March 31, 2020 & 198 & 4.6 & 5.5 & NR \\
\hline 22. & Zhang et al & China & after Jan. 20, 2020 & 35 & 5.1 & 3.4 & $1 \cdot 3-11 \cdot 6$ \\
\hline 23. & Zhao et al & China & February 15,2020 & 21 & 4.4 & 3 & $2.9-6.7$ \\
\hline
\end{tabular}

Table 2 Descriptions of the included studies conducted on the average incubation period of COVID-19, 2020

\begin{tabular}{|c|c|c|c|c|c|c|c|}
\hline No. & First author & Country & Study period & Sample size & Mean in days & Standard deviation & $95 \% \mathrm{Cl}$ \\
\hline 1. & Backer et al & China & January 20 to 28, 2020 & 88 & 6.4 & 3.8 & $5.6-7.7$ \\
\hline 2. & Bi et al & China & Jan 14 to Feb 12, 2020 & 183 & 4.8 & 0.9 & $4 \cdot 2-5 \cdot 4$ \\
\hline 3. & Cheng et al & Taiwan & January 15 to February 26,2020 & 32 & 4.9 & 6.3 & $2.7-8.4$ \\
\hline 4. & Han et al & China & December 29, 2019, to February 5, 2020. & 59 & 5.8 & 2.9 & $5.1-6.5$ \\
\hline 5. & Kong & China & January 22 to February 15, 2020 & 136 & 8.5 & 4.1 & $7.8-9.2$ \\
\hline 6. & Lauer et al & China & January 4 to February 24, 2020. & 181 & 5.1 & 0.97 & $4.5-5.8$ \\
\hline 7. & Li et al & China & January 22, 2020 & 10 & 5.2 & 1.9 & $4.1-7.0$ \\
\hline 8. & Linton et al & China & January 31, 2020 & 158 & 5.6 & 2.8 & $5.0-6.3$ \\
\hline 9. & Tindale et al & Singapore & January 19 to February 26,2020 & 93 & 7.1 & 4.9 & $6.1-8.3$ \\
\hline 10. & Tindale et al & Tianjin & January 21 to February 27,2020 & 135 & 9.0 & 6.5 & $7.9-10.2$ \\
\hline 11. & Viego et al & Argentina & March 20 to May 8, 2020 & 12 & 7.5 & 5.9 & $4.1-10.9$ \\
\hline 12. & Yang et al & China & January 20, 2020 & 178 & 8.5 & 3.8 & $4.8-6.0$ \\
\hline 13. & You et al & China & March 31, 2020 & 139 & 8 & 4.8 & NR \\
\hline 14. & Zhang et al & China & after Jan. 20, 2020 & 49 & 5.2 & 12.1 & $1 \cdot 8-12 \cdot 4$ \\
\hline
\end{tabular}




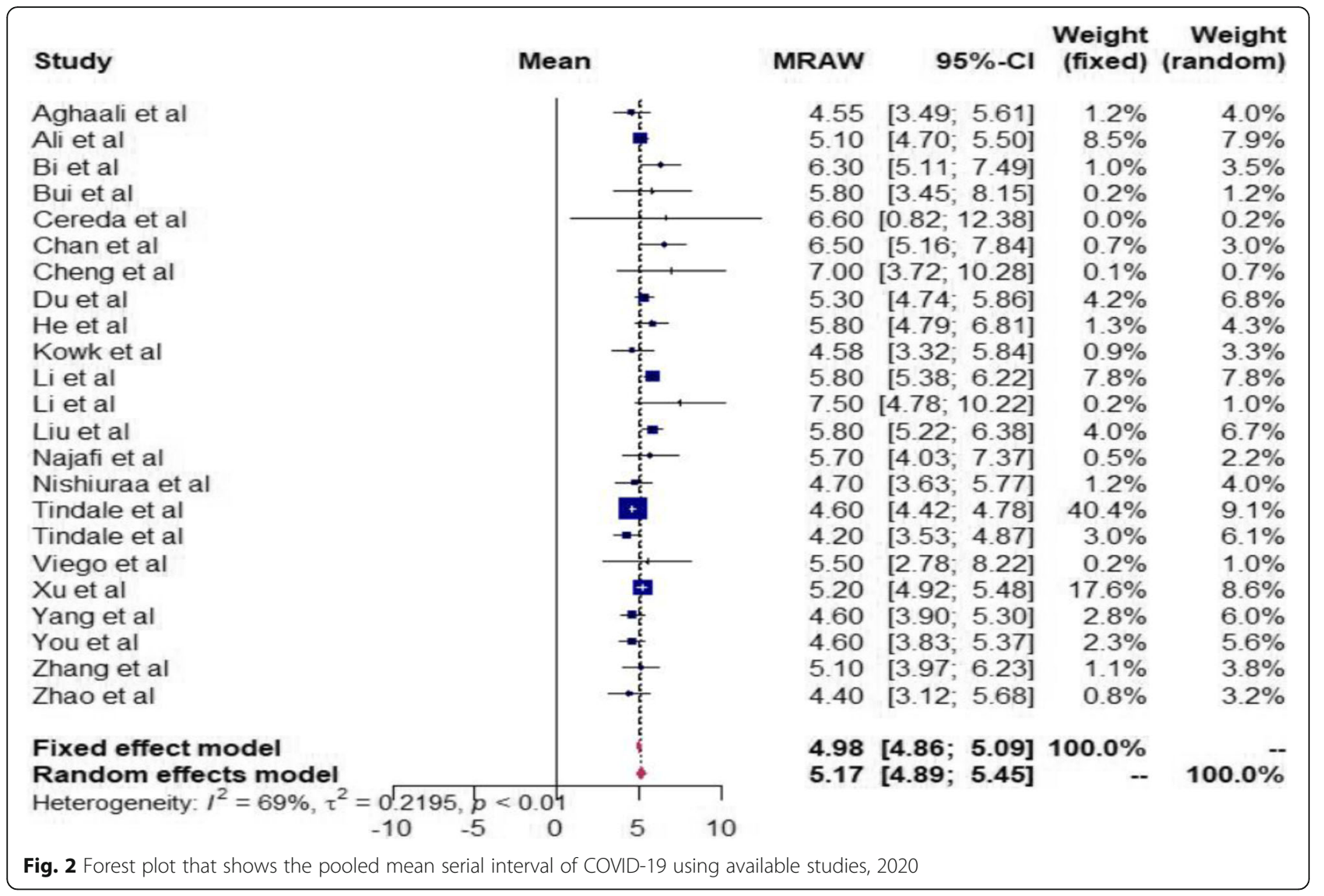

COVID-19. In this study, we found that the weighted pooled mean serial interval of COVID-19 was 5.2 (95\%CI: 4.9-5.5) days. This result is consistent with a study conducted in China [21], which reported that the mean serial interval of 5.35 (95\%CI: 4:63; 6:07) days. Another systematic review and meta-analysis study that combines 11 studies reported that the mean serial interval of 5.19 (95\%CI: 4.37, 6.02) [22]. A study that compares the epidemiology of COVID-19, SARS-CoV, and MERS-CoV showed that COVID-19 had a short serial interval than SARS and MERS [23]. In addition, the pooled mean serial interval of COVID-19 obtained in this study is shorter than the mean serial interval of MERS and SARS reported in South Korea, and Singapore [24, 25].

The second objective of this study was to determine the overall mean incubation period of COVID-19. Consequently, the weighted pooled mean incubation period of COVID-19 was found 6.5 (95\%CI: 5.9-7.1) days. This result is consistent with a study conducted in Hong Kong [26]. A result obtained from a rapid systematic review and meta-analysis showed that median incubation period of COVID-19 is 5.1 (95\% CI: 4.5-5.8) days. Furthermore, the average incubation period of COVID-19 obtained in this study is longer than the average incubation period of SARS that reported in Toronto, Hong Kong, and Beijing [24, 27]. In addition, the average incubation period of COVID-19 obtained in the current study is longer than a systematic review study that reported the average incubation period of SARS [28].

Moreover, the average incubation period of COVID-19 obtained in the current study is longer than the mean incubation period of MERS reported in Hong Kong, and the Middle East [29, 30]. The possible explanation for this result might be the associations between shorter incubation periods and greater severity of infectious disease [31]. A longer incubation period was associated with a reduction in the risk of death [32]. The estimated fatality rate of COVID-19, SARS, and MERS are 2.3, 9.5, and $34.4 \%$, respectively [33-35]. Conversely, another study showed that there is no observable difference between the incubation periods for SARS-CoV-2, severe acute respiratory syndrome coronavirus (SARS-CoV), and MERS-CoV. This study reported that the estimated incubation periods for SARS-CoV-2, SARS-CoV, and MERS-CoV were 4.9, 4.7, and 5.8 days, respectively [11].

In the current study, we included more studies by making longer searching date than the previous published articles. As the number of studies in meta-analysis 


\begin{tabular}{|c|c|c|c|c|c|c|}
\hline Study & & & MRAW & $95 \%-\mathrm{Cl}$ & $\begin{array}{l}\text { Weight } \\
\text { (fixed) ( }\end{array}$ & $\begin{array}{r}\text { Weight } \\
\text { (random) }\end{array}$ \\
\hline Backer et al & & & 6.40 & {$[5.61 ; 7.19]$} & $1.2 \%$ & $7.6 \%$ \\
\hline Bi et al & + & & 4.80 & {$[4.67 ; 4.93]$} & $45.2 \%$ & $8.7 \%$ \\
\hline Cheng et al & & & 4.90 & {$[2.72 ; 7.08]$} & $0.2 \%$ & $4.2 \%$ \\
\hline Han et al & + & & 5.80 & {$[5.06 ; 6.54]$} & $1.4 \%$ & $7.7 \%$ \\
\hline Kong & & $\rightarrow$ & 8.50 & {$[7.81 ; 9.19]$} & $1.6 \%$ & $7.9 \%$ \\
\hline Lauer et al & + & & 5.10 & {$[4.96 ; 5.24]$} & $38.5 \%$ & $8.7 \%$ \\
\hline Li et al & + & & 5.20 & {$[4.02 ; 6.38]$} & $0.6 \%$ & $6.6 \%$ \\
\hline Linton et al & : & & 5.60 & {$[5.16 ; 6.04]$} & $4.0 \%$ & $8.3 \%$ \\
\hline Tindale et al & & $\leftarrow$ & 7.10 & {$[6.10 ; 8.10]$} & $0.8 \%$ & $7.1 \%$ \\
\hline Tindale et al & & $\rightarrow$ & 9.00[ & {$[7.90 ; 10.10]$} & $0.6 \%$ & $6.8 \%$ \\
\hline Viego et al & $\frac{1}{1}$ & & 7.50 & {$[4.16 ; 10.84]$} & $0.1 \%$ & $2.5 \%$ \\
\hline Yang et al & & + & 8.50 & {$[7.94 ; 9.06]$} & $2.5 \%$ & $8.1 \%$ \\
\hline You et al & & $\rightarrow$ & 8.00 & {$[7.20 ; 8.80]$} & $1.2 \%$ & $7.6 \%$ \\
\hline Zhang et al & + & & 5.20 & {$[4.61 ; 5.79]$} & $2.2 \%$ & $8.1 \%$ \\
\hline Fixed effect model & $i$ & & \multirow{4}{*}{\multicolumn{2}{|c|}{$\begin{array}{l}5.23[5.14 ; 5.32] \\
6.51[5.89 ; 7.13]\end{array}$}} & $100.0 \%$ & -- \\
\hline Random effects model & 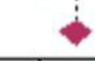 & & & & - & $100.0 \%$ \\
\hline Heterogeneity. $I^{2}=97 \%, \tau^{2}=1.1508, p<0.04$ & & & & & & \\
\hline-10 & 5 & 10 & & & & \\
\hline
\end{tabular}




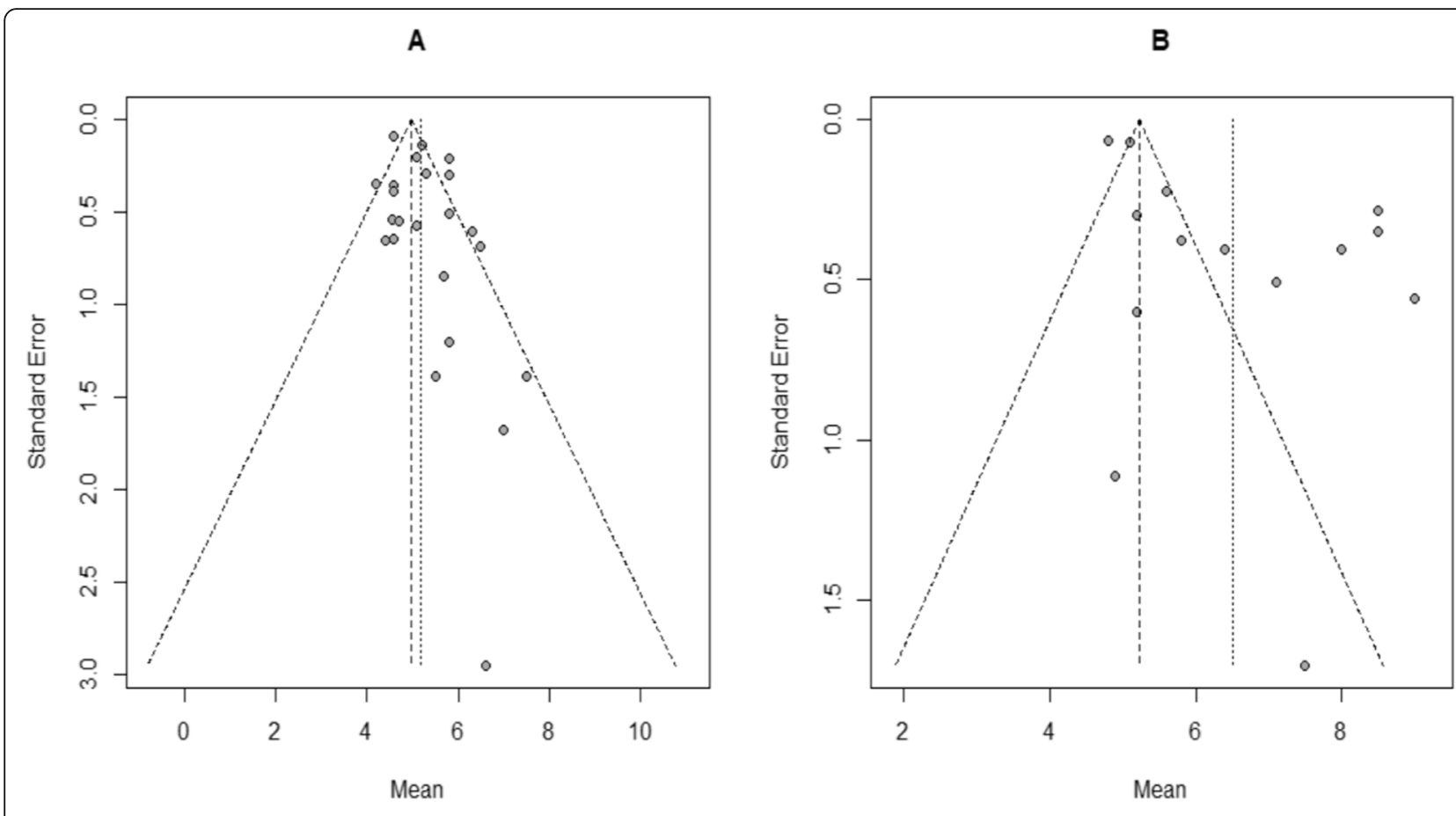

Fig. 4 Funnel plots to check publication bias. a The included studies to pool the mean serial interval of COVID-19. b The included studies to pool the mean incubation period of COVID-19

increases, the power of estimating the pooled serial interval and incubation period of COVID-19 will be improved.

\section{Limitations}

The current study has a number of limitations. Firstly, the overall estimate of serial interval and incubation period were computed with in a considerable heterogeneity. The source of heterogeneity might be difference in study population, data collection period, and method of analysis. Secondly, the majority of the included studies had relatively small study participants which may decrease the power of the study. Thirdly, the review was limited to only articles published in the English language. Lastly, since the included articles are limited to few countries, it may not represent the global figure.

\section{Conclusions}

This systematic review and meta-analysis showed that the weighted pooled mean serial interval and incubation period of COVID-19 were 5.2, and 6.5 days, respectively. The average serial interval of COVID-19 is shorter than the average incubation period, which suggests that substantial numbers of COVID-19 cases will be attributed to presymptomatic or asymptomatic transmission.

\section{Abbreviations}

MERS-CoV: Middle East respiratory syndrome coronavirus; COVID-19: novel coronavirus disease 2019; SARS-CoV-2: Severe Acute Respiratory Syndrome Coronavirus 2

\section{Supplementary Information}

The online version contains supplementary material available at https://doi. org/10.1186/s12879-021-05950-x.

Additional file 1: Table S1. Assessing the risk of bias for the included studies to estimate the pooled avarage of serial interval of COVID-19, 2020.

Additional file 2: Table S2. Assessing the risk of bias for the included studies to estimate the pooled avarage incubation period of COVID-19, 2020.

\section{Acknowledgments}

We would like to thank primary authors.

\section{Authors' contributions}

$M A, L Y$, and MAA: conceived the design; DBK and WG develop the search strategy; MA, LY, MAA and TYB: searched, screened, and appraised the studies, and extract the data: MA analyze the data; MAA, LY, MAA and TYB: drafted the manuscript. All authors read and approved the final manuscript for publication.

Funding

Not applicable.

Availability of data and materials

All the materials and data on which the findings of this review based are presented within the manuscript.

\section{Declarations}

Ethics approval and consent to participate Not applicable.

Consent for publication Not applicable. 


\section{Competing interests}

All authors declared that there is no competing interest.

\section{Author details}

'Department of Public Health, Debre Markos University, Debre Markos, Ethiopia. ${ }^{2}$ Department of Epidemiology and Biostatistics, Institute of Public Health, College of Medicine and Health Science, University of Gondar, Gondar, Ethiopia.

Received: 13 November 2020 Accepted: 2 March 2021

Published online: 11 March 2021

\section{References}

1. WHO. Media briefing on COVID-19 - 2020. Accessed from https://www.who. int/dg/speeches/detail/who-director-general-s-opening-remarks-at-themedia-briefing-on-covid-19---11-march-2020.

2. JHONS HOPKINS coronavirus resource center. COVID-19. Dashboard by the Center for Systems Science and Engineering (CSSE) at Johns Hopkins University (JHU). COVID, Coronavirus research center

3. The world bank. The global economic outlook during the covid-19 pandemic: a changed world; 2020. Accessed from https://www.worldbank org/en/news/feature/2020/06/08/the-global-economic-outlook-during-thecovid-19-pandemic-a-changed-world.

4. Sanders JM, Monogue ML, Jodlowski TZ, Cutrell JB. Pharmacologic treatments for coronavirus disease 2019 (COVID-19): a review. JAMA. 2020; 323(18):1824-36.

5. Gostic K, Gomez AC, Mummah RO, Kucharski AJ, Lloyd-Smith JO. Estimated effectiveness of symptom and risk screening to prevent the spread of COVID-19. Elife. 2020;9:e55570.

6. Read JM, Bridgen JR, Cummings DA, Ho A, Jewell CP. Novel coronavirus 2019-nCoV: early estimation of epidemiological parameters and epidemic predictions. MedRxiv. 2020

7. Chan YW, Flasche S, Lam TL, Leung MH, Wong ML, Lam HY, et al. Transmission dynamics, serial interval and epidemiology of COVID-19 diseases in Hong Kong under different control measures. Wellcome Open Res. 2020;5:91

8. Nishiura $H$, Linton NM, Akhmetzhanov AR. Serial interval of novel coronavirus (COVID-19) infections. Int J Infect Dis. 2020;93:284-6.

9. Viego V, Geri M, Castiglia J, Jouglard E. Incubation period and serial interval of Covid-19 in a chain of infections in Bahia Blanca (Argentina). Ciência Saúde Coletiva. 2020;25(9):3503-10.

10. Ma S, Zhang J, Zeng M, Yun Q, Guo W, Zheng Y, et al. Epidemiological parameters of coronavirus disease 2019: a pooled analysis of publicly reported individual data of 1155 cases from seven countries. Medrxiv. 2020.

11. Jiang X, Rayner S, Luo MH. Does SARS-CoV-2 has a longer incubation period than SARS and MERS? J Med Virol. 2020;92(5):476-8.

12. Moher D, Liberati A, Tetzlaff J, Altman DG, The PRISMA Group. Preferred reporting items for systematic reviews and meta-analyses: the PRISMA statement. PLoS Med. 2009;6(7):e1000097. https://doi.org/10.1371/journal. pmed1000097.

13. Newcastle-Ottawa Scale customized for cross-sectional studies In. available from https://static-content.springer.com/esm/.../12889_2012_5111_ MOESM3_ESM.doc. Accessed 24 July 2020.

14. Wan X, Wang W, Liu J, Tong T. Estimating the sample mean and standard deviation from the sample size, median, range and/or interquartile range. BMC Med Res Methodol. 2014;14(1):135.

15. Melsen WG, Bootsma MC, Rovers MM, Bonten MJ. The effects of clinical and statistical heterogeneity on the predictive values of results from metaanalyses. Clin Microbiol Infect. 2014;20(2):123-9.

16. Van Enst WA, Ochodo E, Scholten RJ, Hooft L, Leeflang MM. Investigation of publication bias in meta-analyses of diagnostic test accuracy: a metaepidemiological study. BMC Med Res Methodol. 2014;14(1):70.

17. Li Q, Guan X, Wu P, Wang X, Zhou L, Tong Y, et al. Early transmission dynamics in Wuhan, China, of novel coronavirus-infected pneumonia. $N$ Engl J Med. 2020. https://doi.org/10.1056/NEJMoa2001316.

18. Xu XK, Liu XF, Wu Y, Ali ST, Du Z, Bosetti P, et al. Reconstruction of transmission pairs for novel coronavirus disease 2019 (COVID-19) in mainland China: estimation of super-spreading events, serial interval, and hazard of infection. Clin Infect Dis. 2020
19. Tindale L, Coombe M, Stockdale JE, Garlock E, Lau WY, Saraswat M, et al. Transmission interval estimates suggest pre-symptomatic spread of COVID19. MedRxiv. 2020

20. Bi Q, Wu Y, Mei S, Ye C, Zou X, Zhang Z, et al. Epidemiology and transmission of COVID-19 in 391 cases and 1286 of their close contacts in Shenzhen, China: a retrospective cohort study. Lancet Infect Dis. 2020;20(8): 911-9.

21. Zhang $P$, Wang $T$, Xie SX. Meta-analysis of several epidemic characteristics of COVID-19. J Data Sci. 2020:18(3):536.

22. Rai B, Shukla A, Dwivedi LK. Estimates of serial interval for COVID-19: a systematic review and meta-analysis. Clin Epidemiol Global Health. 2020

23. Xie M, Chen Q. Insight into 2019 novel coronavirus - an updated intrim review and lessons from SARS-CoV and MERS-CoV. Int J Infect Dis. 2020;94: $119-24$

24. Cowling BJ, Park M, Fang VJ, Wu P, Leung GM, Wu JT. Preliminary epidemiological assessment of MERS-CoV outbreak in South Korea, may to June 2015. Eurosurveillance. 2015;20(25):21163.

25. Lipsitch M, Cohen T, Cooper B, Robins JM, Ma S, James L, et al. Transmission dynamics and control of severe acute respiratory syndrome. Science. 2003; 300(5627):1966-70.

26. Donnelly CA, Ghani AC, Leung GM, Hedley AJ, Fraser C, Riley S, et al. Epidemiological determinants of spread of causal agent of severe acute respiratory syndrome in Hong Kong. Lancet. 2003;361(9371):176.

27. Lau EH, Hsiung CA, Cowling BJ, Chen CH, Ho LM, Tsang T, et al. A comparative epidemiologic analysis of SARS in Hong Kong, Beijing and Taiwan. BMC Infect Dis. 2010;10(1):1-9.

28. Lessler J, Reich NG, Brookmeyer R, Perl TM, Nelson KE, Cummings DA. Incubation periods of acute respiratory viral infections: a systematic review. Lancet Infect Dis. 2009;9(5):291-300.

29. Park JE, Jung S, Kim A. MERS transmission and risk factors: a systematic review. BMC Public Health. 2018:18(1):574.

30. Cauchemez S, Fraser C, Van Kerkhove MD, Donnelly CA, Riley S, Rambaut A, et al. Middle East respiratory syndrome coronavirus: quantification of the extent of the epidemic, surveillance biases, and transmissibility. Lancet Infect Dis. 2014;14(1):50-6.

31. Virlogeux V, Fang VJ, Wu JT, Ho LM, Peiris JM, Leung GM, et al. Incubation period duration and severity of clinical disease following severe acute respiratory syndrome coronavirus infection. Epidemiology. 2015;26(5):666.

32. Virlogeux V, Park M, Wu JT, Cowling BJ. Association between severity of MERS-CoV infection and incubation period. Emerg Infect Dis. 2016;22(3):526.

33. Petrosillo N, Viceconte G, Ergonul O, Ippolito G, Petersen E. COVID-19, SARS and MERS: are they closely related? Clin Microbiol Infect. 2020;26:729-34.

34. Pormohammad A, Ghorbani S, Khatami A, Farzi R, Baradaran B, Turner DL, et al. Comparison of confirmed COVID-19 with SARS and MERS cases-clinical characteristics, laboratory findings, radiographic signs and outcomes: a systematic review and meta-analysis. Rev Med Virol. 2020;30(4):e2112.

35. Lu L, Zhong W, Bian Z, Li Z, Zhang K, Liang B, et al. A comparison of mortality-related risk factors of COVID-19, SARS, and MERS: a systematic review and meta-analysis. J Infect. 2020

\section{Publisher's Note}

Springer Nature remains neutral with regard to jurisdictional claims in published maps and institutional affiliations.

Ready to submit your research? Choose BMC and benefit from

- fast, convenient online submission

- thorough peer review by experienced researchers in your field

- rapid publication on acceptance

- support for research data, including large and complex data types

- gold Open Access which fosters wider collaboration and increased citations

- maximum visibility for your research: over $100 \mathrm{M}$ website views per year

At BMC, research is always in progress.

Learn more biomedcentral.com/submission 